\title{
Hydrothermal Synthesis and Microstructural, Optical Properties Characterization of $\mathrm{YVO}_{4}$ Phosphor Powder
}

\author{
S. ZHANG ${ }^{a}$, Y. LIANG ${ }^{b}$, X.-Y. GAO ${ }^{a, *}$ AND H.-T. LIU ${ }^{a}$ \\ ${ }^{a}$ Key Laboratory of Materials Physics of Ministry of Education, School of Physics and Engineering \\ Zhengzhou University, 450052 Zhengzhou, China \\ ${ }^{b}$ College of Information Science and Engineering, Henan University of Technology, 450001 Zhengzhou, China
}

(Received June 13, 2013; in final form November 20, 2013)

\begin{abstract}
The phonon energy of $\mathrm{YVO}_{4}$ crystal is lower than other usual compounds of salt. So it is suitable as host material for down-conversion materials. Hydrothermal method was adopted to synthesize $\mathrm{YVO}_{4}$ phosphor powder with the use of yttrium oxide and sodium vanadate as raw material. The change in the relative integral intensity of the (200) and (112) diffraction peaks indicates that macroscopic stress in the lattice obviously changes with the elevated hydrothermal reaction temperature. The $\mathrm{YVO}_{4}$ phosphor powder synthesized involves a certain agglomeration of small particles. The phonon vibration in the $\mathrm{YVO}_{4}$ originates mainly from the internal vibrations in the vanadium-oxygen tetrahedron, in addition to the $\mathrm{Y}-\mathrm{O}$ and $\mathrm{O}-\mathrm{H}$ vibrations. Due to a low phonon energy of only $2.8188 \times 10^{-21} \mathrm{~J}, \mathrm{YVO}_{4}$ helps to improve the down-conversion efficiency of rare-earth ions. A bandgap value of approximately $3.8 \mathrm{eV}$ for the synthesized $\mathrm{YVO}_{4}$ powders leads to good absorption properties in the ultraviolet region. Upon excitation by the $320 \mathrm{~nm}$ ultraviolet photon, the intrinsic emission of $\mathrm{YVO}_{4}$ powders is annihilated, and a broadband emission of $\mathrm{VO}_{4}^{3-}$ near $450 \mathrm{~nm}$ is observed at room temperature. The $\mathrm{YVO}_{4}$ phosphor powder synthesized at $180^{\circ} \mathrm{C}$ exhibits the maximum photoluminescence intensity because of its excellent crystallization.
\end{abstract}

DOI: 10.12693/APhysPolA.125.105

PACS 78.55.-m, 42.70.Hj, 78.67.-n

\section{Introduction}

In the recent years, much research attention has been paid to yttrium vanadate $\left(\mathrm{YVO}_{4}\right)$ because of its high chemical and thermal stability as well as low phonon energy. It has been widely used as a matrix material in the field of lighting, optical devices, and diode pumped solid state lasers. For example, $\mathrm{YVO}_{4}: \mathrm{Eu}^{3+}$ is a steadfast luminescent material used in color television, the high-pressure mercury lamp and as a scintillator in medical image detectors for more than 20 years [1]. $\mathrm{Nd}^{\mathrm{Y}} \mathrm{YVO}_{4}$ crystal rather than Nd:YAG has been commercialized as laser device for its excellent monochromaticity and stability [2]. Forbes et al. [3] reported the synthesis, solubility and growth of large $\mathrm{YVO}_{4}$ and $\mathrm{Nd}: \mathrm{YVO}_{4}$ transparent single crystals in aqueous $\mathrm{NaOH}$ under hydrothermal conditions. Moreover, $\mathrm{YVO}_{4}$ also has certain academic and applied research value as matrix material for down-conversion in crystalline silicon cells. As crystalline silicon cells remain the most dominant solar cell products in the market [4], to achieve large-scale civilian use of crystalline silicon cells, the utilization of solar spectrum, photoelectric conversion efficiency, stability and service life need to be improved. Although photons with energy larger than the silicon band gap can be absorbed, absorption of the ultraviolet photons will increase the internal temperature of the silicon cells. Heat emission inside the

\footnotetext{
*corresponding author; e-mail: xygao@zzu.edu.cn
}

cells leads to a decline in cell efficiency, which also affects the stability and service life of battery components. Moreover, the encapsulation glass of battery components can absorb a part of ultraviolet photons, which will reduce the use of ultraviolet photons for solar cells. These phenomena directly limit the further application of crystalline silicon cells [5].

However, a down-conversion mechanism, which is realized by converting a high-energy photon into two or more low-energy photons by using the abundant energy level structure of the rare-earth ions [6], can be used to solve these problems. The down-conversion process is generally realized by doping suitable rare-earth ions into a matrix material with a wide band gap. Efficient energy transfer and conversion between the matrix material and rare-earth ions can be achieved.

For rare-earth ions doped materials, ultraviolet photons with poor response in the solar spectrum can be converted to visible and near-infrared photons that can be easily absorbed by crystalline silicon cells. Through this approach, the loss of ultraviolet photons through encapsulation glass can be reduced and the energy utilization of photons in the ultraviolet region can be enhanced. Thus, the decline in stability of solar cells caused by the direct absorption of ultraviolet photons can be prevented.

A number of studies on single-doped and co-doped rare-earth ions into $\mathrm{YVO}_{4}$ matrix material have been carried out recently. For example, $\mathrm{Ln}^{3+}(\mathrm{Ln}=\mathrm{Eu}$, Dy, Sm, and Er) ion-doped $\mathrm{YVO}_{4}$ nano/microcrystals with multiform morphologies synthesized by hydrothermal method has been reported by Xu et al. [7] in 2010 . The spectral conversion for solar cell efficiency enhance- 
ment using $\mathrm{YVO}_{4}: \mathrm{Bi}^{3+}, \mathrm{Ln}^{3+}(\mathrm{Ln}=\mathrm{Dy}, \mathrm{Er}, \mathrm{Ho}, \mathrm{Eu}$, $\mathrm{Sm}$, and $\mathrm{Yb}$ ) phosphors synthesized by high-temperature solid phase method has been reported by Huang et al. [8] in 2011. A rapid preparation of $\mathrm{YVO}_{4}: \mathrm{Eu}^{3+}$ films by microwave irradiation assisted chemical bath deposition has been reported by Xu et al. [9] in 2005. Of course, the down-conversion phenomena of rare-earth doped materials have also been achieved in various other matrix materials, such as borate [10], phosphate [11] and silicate [12].

Although several methods can be used to synthesize down-conversion materials, a hydrothermal method with the advantages of mild reaction conditions, low cost, simple process, and less vulnerability to pollution compared with the other methods mentioned above has been widely used in the synthesis of rare-earth doped $\mathrm{YVO}_{4}$ materials. Athough the down-conversion materials of rare-earth doped $\mathrm{YVO}_{4}$ material has been widely studied, the intrinsic properties of $\mathrm{YVO}_{4}$, especially the photoluminescence properties and vibration modes of internal chemical bonds, has not been fully understood yet.

In this paper, authors especially focused on the study of the photoluminescence properties and the internal vibration modes of $\mathrm{YVO}_{4}$ phosphor powder matrix material synthesized by hydrothermal method. The effect of the hydrothermal reaction temperature (HRT) on the microstructure and the optical properties especially photoluminescence property of the phosphor powder were in detail studied on purpose that the study can provide theoretical and experimental basis for further research of rare-earth doped $\mathrm{YVO}_{4}$ down-conversion luminescent material used in crystal silicon cells.

\section{Experimental procedure}

A suitable amount of $\mathrm{Y}_{2} \mathrm{O}_{3}(99.99 \%)$ was dissolved in hydrochloric acid at an elevated temperature to prepare $0.2 \mathrm{M} \mathrm{YCl}_{3}$ solution, $20 \mathrm{~mL}$ of which was added into a beaker containing $40 \mathrm{~mL}$ deionized water. Then, $0.004 \mathrm{~mol}$ of $\mathrm{Na}_{3} \mathrm{VO}_{4}(99.99 \%)$ was introduced into the solution. After vigorous stirring for $1 \mathrm{~h}$, the as-obtained solution was transferred into a Teflon bottle in a stainless steel autoclave, sealed, and maintained at different HRTs $\left(120,140,160,180\right.$, and $\left.200^{\circ} \mathrm{C}\right)$ for $24 \mathrm{~h}$. The autoclave was allowed to cool to room temperature naturally. The precipitates were separated by centrifugation, washed with ethanol and deionized water for several times in sequence, and then dried in air at $80^{\circ} \mathrm{C}$ for $12 \mathrm{~h}$. Subsequently, the $\mathrm{YVO}_{4}$ phosphor powder matrix materials of the HRT series were obtained.

The crystallization, vibration modes, and surface morphology of the $\mathrm{YVO}_{4}$ phosphor powders were determined through X-ray diffraction (XRD, Philips PANA-lytical X'pert), cold-field scanning electron microscopy (CF-SEM, JEOL-JSM-6700F), Raman spectroscopy (Renishaw 2000), and Fourier transform infrared spectroscopy (FTIR, Nicolet NEXUS-470), respectively. The Scherrer formula was used to calculate the average grain size and lattice microscopic distortion of the phosphor powder.
Absorption and luminescence properties were measured through a spectrophotometer (ShimadzuUV-3150) and a spectrofluorometer (FluoroMax-4), respectively. All measurements were carried out at room temperature.

\section{Results and discussion}

\subsection{Crystallization, vibration modes, and surface morphology}

Figure 1 shows the XRD patterns of the $\mathrm{YVO}_{4}$ phosphor powders synthesized by using the hydrothermal method at different HRTs. The products synthesized at different HRTs exhibit the tetragonal and polycrystalline structure of the $\mathrm{YVO}_{4}$ phase in accordance with the standard diffraction pattern (JCPDS 17-0341). No miscellaneous peak is observed among all the diffraction peaks, indicating that the products are of high purity. The relative integral intensity of the (200) and (112) diffraction peaks gradually decreases with the increase in HRT, with the value abnormally reaching its maximum at $180^{\circ} \mathrm{C}$. This phenomenon indicates that macroscopic stress in the lattice changes with the elevated HRT.

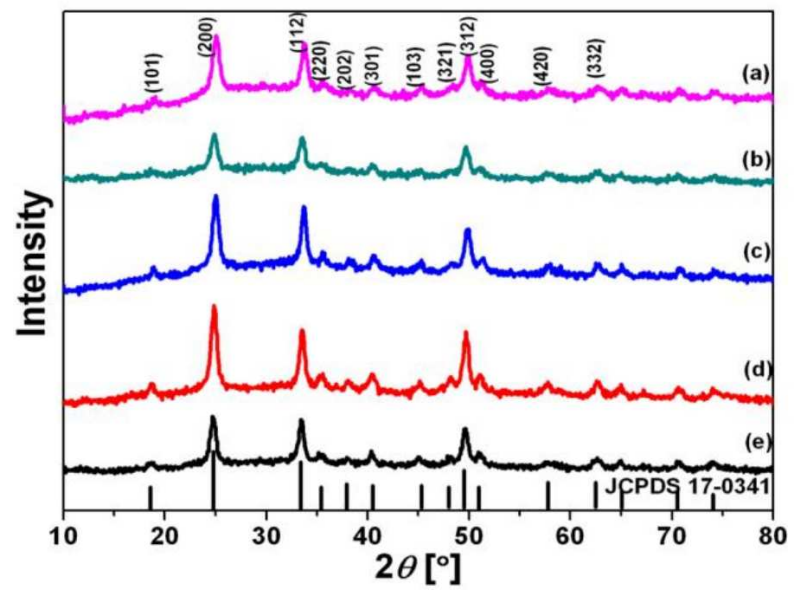

Fig. 1. XRD patterns of the $\mathrm{YVO}_{4}$ phosphor powders synthesized using the hydrothermal method at HRTs of (a) $120^{\circ} \mathrm{C},\left(\right.$ b) $140{ }^{\circ} \mathrm{C},(c) 160{ }^{\circ} \mathrm{C},(d) 180{ }^{\circ} \mathrm{C},($ e $) 200{ }^{\circ} \mathrm{C}$.

Grain refinement and lattice microscopic distortion lead to XRD-peak broadening. Thus, the full width at half maximum (FWHM) of the XRD diffraction peak of the samples must be corrected when using XRD to characterize the grain size and lattice strain with FWHM can be expressed in accordance with the Williamson-Hall relationship [13, 14]:

$$
\begin{aligned}
& \beta \cos \theta=\lambda / D+4 \Delta d / d \sin \theta, \\
& \beta^{2}=\beta_{\mathrm{M}}^{2}-\beta_{\mathrm{S}}^{2},
\end{aligned}
$$

where $\beta$ is the FWHM of the diffraction peak caused by the grain refinement and lattice microscopic distortion. $\lambda$ is the wavelength of the X-ray, $\theta$ is the Bragg angle, $D$ is the average grain size, $d$ is the spacing between crystal planes, and $\Delta d / d$ is the lattice microscopic distortion. 
$\beta_{\mathrm{M}}$ and $\beta_{\mathrm{S}}$ are measured FWHM value of the sample and FWHM of standard sample, respectively.

The average grain size and lattice microscopic distortion of the $\mathrm{YVO}_{4}$ phosphor powders synthesized under different HRTs are shown in Table I. The average grain size of the $\mathrm{YVO}_{4}$ phosphor powder slightly changes by almost $13 \mathrm{~nm}$ as the HRT increases. Moreover, a smaller average grain size results in a larger lattice strain, which is due to the enhanced surface effect [15].

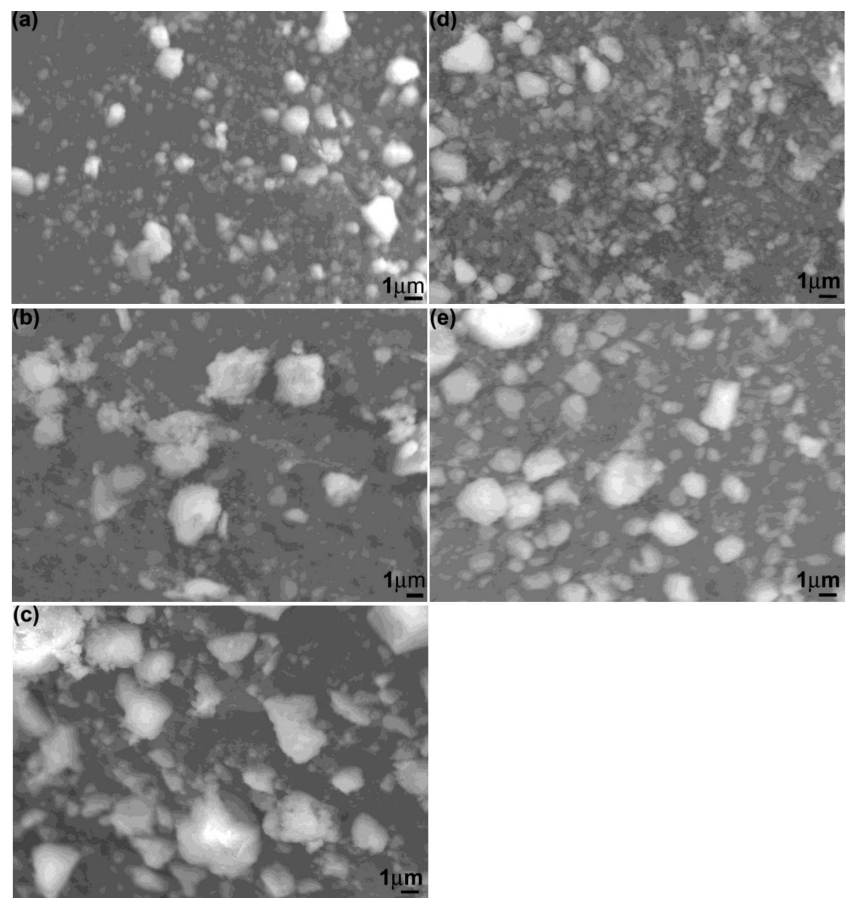

Fig. 2. SEM images of the $\mathrm{YVO}_{4}$ phosphor powders synthesized at HRTs of (a) $120^{\circ} \mathrm{C}$, (b) $140{ }^{\circ} \mathrm{C}$, (c) $160^{\circ} \mathrm{C}$, (d) $180{ }^{\circ} \mathrm{C},\left(\right.$ e) $200^{\circ} \mathrm{C}$.

TABLE I

Average grain size and lattice microscopic distortion of the $\mathrm{YVO}_{4}$ phosphor powders.

\begin{tabular}{c|c|c}
\hline \hline HRT $\left[{ }^{\circ} \mathrm{C}\right]$ & $D[\mathrm{~nm}]$ & $\Delta d / d[\%]$ \\
\hline 120 & 12.2 & 1.499 \\
140 & 15.8 & 1.198 \\
160 & 12.2 & 1.499 \\
180 & 12.3 & 1.408 \\
200 & 13.8 & 1.362
\end{tabular}

Figure 2 presents the SEM images of the $\mathrm{YVO}_{4}$ phosphor powders synthesized at different HRTs. The phosphor powder synthesized by the hydrothermal method reveals a certain agglomeration of small particles. The particle size is approximately in the micrometer scale. Thus, information on the size and shape of monodispersed particle cannot be obtained from the diagram. These phenomena are related to the randomness of crystal growth along each orientation during the hydrothermal reaction

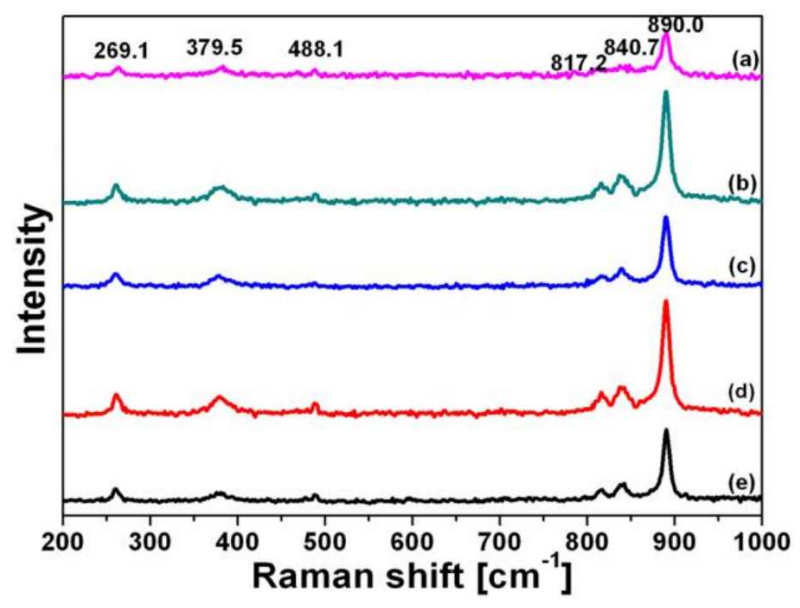

Fig. 3. Raman spectra of the $\mathrm{YVO}_{4}$ phosphor powders synthesized at HRTs of $(a) 120^{\circ} \mathrm{C},(b) 140{ }^{\circ} \mathrm{C},(c) 160^{\circ} \mathrm{C}$, (d) $180{ }^{\circ} \mathrm{C},(e) 200{ }^{\circ} \mathrm{C}$.

process. This is consistent with the XRD patterns shown in Fig. 1.

Figure 3 shows the Raman spectra of the $\mathrm{YVO}_{4}$ phosphor powder synthesized at different HRTs. $\mathrm{YVO}_{4}$, a uniaxial crystal belonging to the tetragonal zircon-type structure, is assigned to the space group of $D_{4 h}^{19}$ and the point group of $D_{4 h}$. The crystal has four kinds of Raman-active vibration modes, including $A_{1 \mathrm{~g}}, B_{1 \mathrm{~g}}, B_{2 \mathrm{~g}}$, and $E_{\mathrm{g}}$. The six Raman shift peaks of this crystal are located at $261.9,379.5,488.1,817.2,840.7$, and $890.0 \mathrm{~cm}^{-1}$ (Fig. 3), which is consistent with the literature [16, 17]. The six peaks originate from the internal vibrations of the vanadium-oxygen tetrahedron. The vibration symmetry and vibration modes of the Raman shift peaks of $\mathrm{YVO}_{4}$ crystal synthesized under our experimental conditions were listed in Table II.

TABLE II

Vibration symmetry and vibration modes of the Raman shift peaks of $\mathrm{YVO}_{4}$ phosphor powder.

\begin{tabular}{|c|c|c|}
\hline $\begin{array}{c}\text { Raman shift } \\
{\left[\mathrm{cm}^{-1}\right]}\end{array}$ & Symmetry & Vibration modes \\
\hline 261.9 & $B_{1 \mathrm{~g}}$ & $\begin{array}{l}\text { symmetrically stretching } \\
\text { vibration in } \mathrm{VO}_{4}^{3-}\end{array}$ \\
\hline 379.5 & $A_{1 \mathrm{~g}}$ & $\begin{array}{l}\text { symmetrically deformation } \\
\text { vibration in } \mathrm{VO}_{4}^{3-}\end{array}$ \\
\hline 488.1 & $B_{1 \mathrm{~g}}$ & $\begin{array}{l}\text { antisymmetrically stretching } \\
\text { vibration in } \mathrm{VO}_{4}^{3-}\end{array}$ \\
\hline 817.2 & $B_{1 \mathrm{~g}}$ & $\begin{array}{c}\text { symmetrically stretching } \\
\text { vibration in } \mathrm{VO}_{4}^{3-}\end{array}$ \\
\hline 840.7 & $E_{\mathrm{g}}$ & $\begin{array}{c}\text { antisymmetrically deformation } \\
\text { vibration in } \mathrm{VO}_{4}^{3-}\end{array}$ \\
\hline 890.0 & $A_{1 \mathrm{~g}}$ & $\begin{array}{l}\text { symmetrically stretching } \\
\text { vibration in } \mathrm{VO}_{4}^{3-}\end{array}$ \\
\hline
\end{tabular}

Table III demonstrates the maximum phonon energy of various common down-conversion matrix materials. 
TABLE III

Maximum phonon energy of various common down-conversion matrix materials.

\begin{tabular}{c|c}
\hline \hline Matrix material & Phonon energy $\left[10^{-21} \mathrm{~J}\right]$ \\
\hline borate & 4.4341 \\
phosphate & 3.4839 \\
silicate & $3.1672-3.4839$ \\
germanate & $2.5338-3.0880$ \\
yttrium vanadate & 2.8188 \\
tellurate & $1.9003-2.6921$
\end{tabular}

The Raman spectra (Fig. 3) and Table II show that the phonon energy of $\mathrm{YVO}_{4}$ is only $2.8188 \times 10^{-21} \mathrm{~J}$ (converted from the maximum phonon energy in the Raman spectroscopy), which is lower than other usual compounds of salt. The $\mathrm{YVO}_{4}$ matrix material with lower phonon energy will generate less heat when joining in the down-conversion process, which is helpful in improving the down-conversion efficiency of rare earth ions-doped $\mathrm{YVO}_{4}$ phosphor powder. Thus, $\mathrm{YVO}_{4}$ is suitable as a down-conversion matrix material.

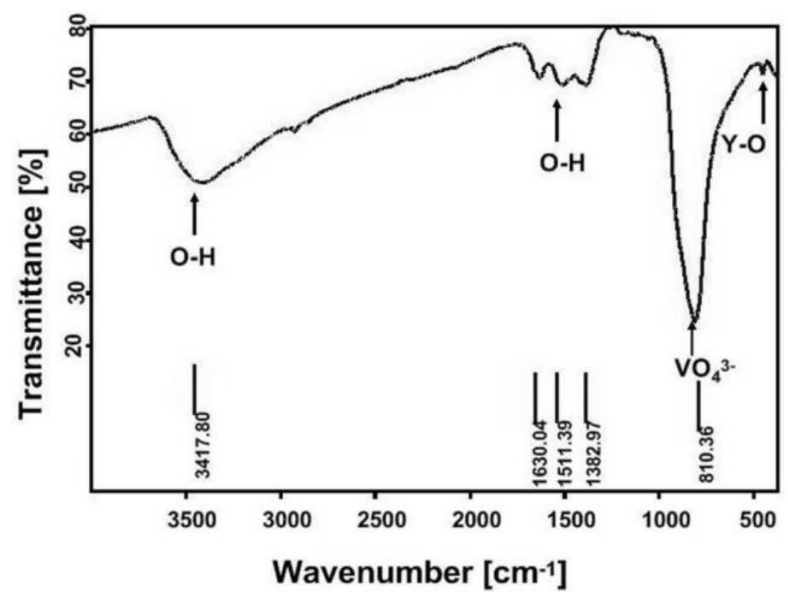

Fig. 4. FTIR spectrum of the $\mathrm{YVO}_{4}$ phosphor powder synthesized at $180^{\circ} \mathrm{C}$.

Figure 4 presents the FTIR spectrum of the $\mathrm{YVO}_{4}$ phosphor powder synthesized at $180^{\circ} \mathrm{C}$. The characteristic $810.36 \mathrm{~cm}^{-1}$ absorption peak corresponds to the strong $\mathrm{VO}_{4}^{3-}$ absorption band in the region of $780 \mathrm{~cm}^{-1}$ to $920 \mathrm{~cm}^{-1}$ [18]. Combined with the Raman spectrum, the absorption band may be caused by the superposition of the three characteristic peaks at 817.2, 840.7, and $890.0 \mathrm{~cm}^{-1}$. The $810.36 \mathrm{~cm}^{-1}$ absorption peak is attributed to the tetrahedral structure of $\mathrm{VO}_{4}^{3-}$, which indicates that the crystal structure of the sample is consistent with the tetragonal structure of $\mathrm{YVO}_{4}$. The weak absorption peaks that appear in the range of $3300 \mathrm{~cm}^{-1}$ to $3500 \mathrm{~cm}^{-1}$ and $1350 \mathrm{~cm}^{-1}$ to $1700 \mathrm{~cm}^{-1}$ are attributed to $\mathrm{O}-\mathrm{H}$ absorption. Moisture absorption by the samples mainly causes these peaks, which will disappear after heat treatment [19].
The hydroxyl ions are also assumed to enter the crystals from air during the growth process. The fact that the absorption band in the range of $3300 \mathrm{~cm}^{-1}$ to $3500 \mathrm{~cm}^{-1}$ belongs to $\mathrm{OH}^{-}$has been proved using the method of isotopic substitution by Kovács et al. [20]. The weak absorption peak at $450 \mathrm{~cm}^{-1}$ could be attributed to $\mathrm{Y}-\mathrm{O}$ absorption. The FTIR spectra of $\mathrm{YVO}_{4}$ phosphor powder synthesized at other HRTs are basically similar to Fig. 4, with only a slight difference in intensity.

\subsection{Optical properties}

Absorption property, particularly in the region of ultraviolet and visible light, was tested using a spectrophotometer. The range of the test wavelength is $200 \mathrm{~nm}$ to $800 \mathrm{~nm}$, and the results are shown in Fig. 5. The absorption edge of $\mathrm{YVO}_{4}$ phosphor powders synthesized at different HRTs is almost $326 \mathrm{~nm}$ (i.e. band gap of approximately $3.8 \mathrm{eV}$ ), which is close to the wavelength limit of its intrinsic absorption transition. The effect of HRT on the absorption edge is not obvious. The ultraviolet absorption band is attributed to $\mathrm{VO}_{4}^{3-}$ absorption. However, differences are found for phosphor powder in the visible region absorption. The $\mathrm{YVO}_{4}$ phosphor powder synthesized at $180^{\circ} \mathrm{C}$ has better absorption properties in the visible region than the other $\mathrm{YVO}_{4}$ phosphor powder materials synthesized at different HRTs.

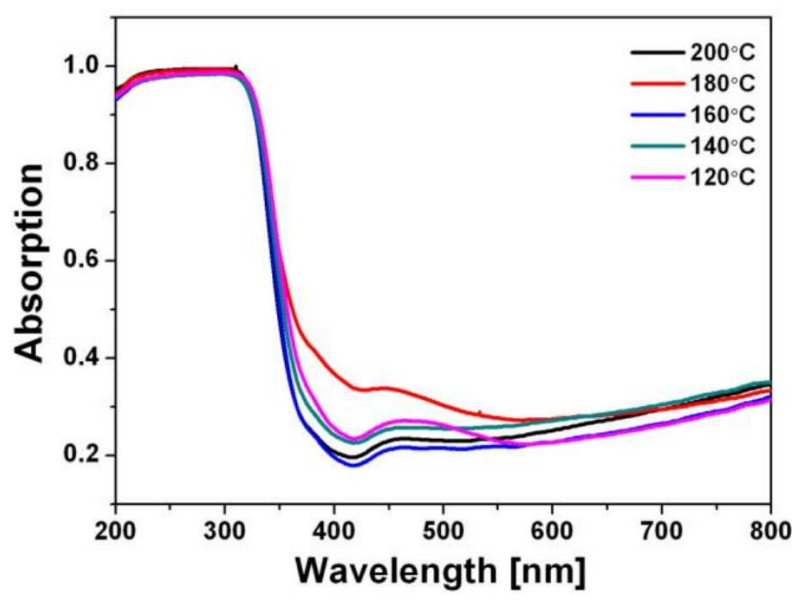

Fig. 5. Absorption spectra of the $\mathrm{YVO}_{4}$ phosphor powders synthesized at different HRTs.

Figure 6 shows the photoluminescence spectra of the $\mathrm{YVO}_{4}$ phosphor powders synthesized at different HRTs. A broad band emission extending from $350 \mathrm{~nm}$ to $650 \mathrm{~nm}$ is observed under the excitation of the $320 \mathrm{~nm}$ ultraviolet photon. The emission peaks are near $450 \mathrm{~nm}$. The emission band observed in our experiment is in agreement with the emission of $\mathrm{VO}_{4}^{3-}$ reported in the literature [21].

The photoluminescence of pure $\mathrm{YVO}_{4}$ are due to these transitions within the $\mathrm{VO}_{4}^{3-}$ ion since similar results are observed from "isolated" vanadate ions in similar hosts such as $\mathrm{YPO}_{4}[22]$. The $\mathrm{VO}_{4}^{3-}$ molecular ions have $T_{d}$ symmetry and a vanadium-oxygen spacing of $1.72 \AA$. 


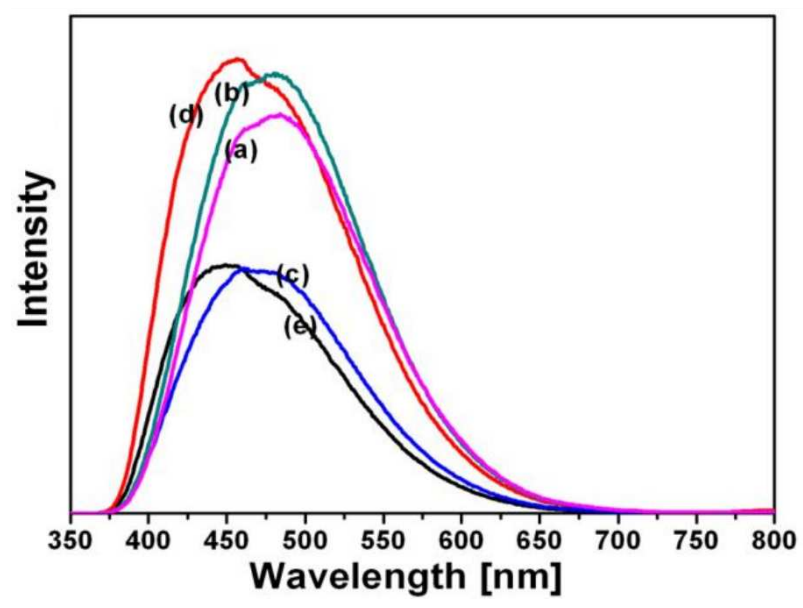

Fig. 6. Photoluminescence spectra of the $\mathrm{YVO}_{4}$ phosphor powder synthesized at HRTs of $(a) 120^{\circ} \mathrm{C}$, (b) $140{ }^{\circ} \mathrm{C},(c) 160{ }^{\circ} \mathrm{C},(d) 180^{\circ} \mathrm{C},(e) 200{ }^{\circ} \mathrm{C}$.

When the vanadate ion is put into the $\mathrm{YVO}_{4}$ crystal, its $T_{d}$ symmetry is reduced to $D_{2 d}$ by the crystal field. This causes a splitting of some of the degenerate energy levels [23].

The photoluminescence observed in our experiment is attributed to the following steps. First, the $\mathrm{VO}_{4}^{3-}$ that absorbs an ultraviolet photon is excited from the filled oxygen $2 p$ levels in the valence band to the empty $\mathrm{V} 3 d$ levels of the conduction band. Second, the electrons in the excited state undergo Stokes shift and relax to the metastable state (i.e. the splitting levels) by the non-radiation transition of emitting different energy phonons. Finally, the excited electrons relax to the ground state by emitting a blue-green photon.

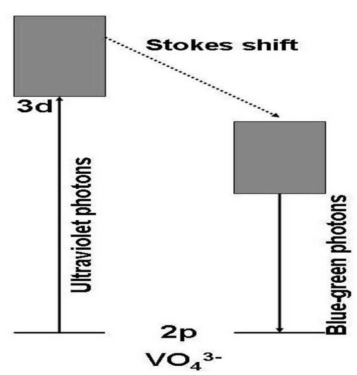

Fig. 7. The energy transfer diagram between ultraviolet photons and $\mathrm{VO}_{4}^{3-}$.

Figure 7 shows the diagram of the energy transfer model. Pankratov et al. [24] reported an emission band near $3.1 \mathrm{eV}$ in the intrinsic emission spectrum of $\mathrm{YVO}_{4}$ crystal at a low temperature $(80 \mathrm{~K})$ in 2007 . The intrinsic emission whose lifetime is shorter than that of the blue band emission is annihilated when the temperature is higher than $150 \mathrm{~K}$ [24]. This is consistent with the result of the non-intrinsic emission of the $\mathrm{YVO}_{4}$ matrix materials in the PL spectra.
Figure 6 reveals that the $\mathrm{YVO}_{4}$ phosphor powder synthesized at $180{ }^{\circ} \mathrm{C}$ exhibits the maximum photoluminescence intensity. This is associated with the lower defect density caused by the higher crystalline quality under $180^{\circ} \mathrm{C}$ than the other HRTs in our experiment. The lower defect density directly leads to the decrease in non-radiative recombination. Thus, the photoluminescence intensity of radiative recombination shows the maximum value under $180^{\circ} \mathrm{C}$.

\section{Conclusion}

In this study, $\mathrm{YVO}_{4}$ phosphor powders were synthesized using the hydrothermal method. The effect of HRT on the microstructure and the optical properties of the $\mathrm{YVO}_{4}$ phosphor powders were analyzed, and the following conclusions were drawn:

(1) The macroscopic stress in the lattice of $\mathrm{YVO}_{4}$ obviously changes with the elevated HRT. Moreover, a smaller average grain size results in a larger lattice microscopic distortion, which is due to the enhanced surface effect.

(2) The $\mathrm{YVO}_{4}$ phosphor powder synthesized by hydrothermal method involves a certain agglomeration of small particles. The size of the particle is approximately in the micrometer scale. These phenomena are related to the randomness of crystal growth along each orientation during the hydrothermal process.

(3) The phonon vibration in the $\mathrm{YVO}_{4}$ crystal lattice originates mainly from the internal vibrations in the vanadium-oxygen tetrahedron, in addition to the $\mathrm{Y}-\mathrm{O}$ and $\mathrm{O}-\mathrm{H}$ vibrations. Among the various kinds of common down-conversion matrix materials, $\mathrm{YVO}_{4}$ crystal has low phonon energy of only $2.8188 \times 10^{-21} \mathrm{~J}$, which helps to improve the down-conversion efficiency of rare earth ions-doped $\mathrm{YVO}_{4}$ phosphor powder.

(4) The band gap of approximately $3.8 \mathrm{eV}$ for the $\mathrm{YVO}_{4}$ synthesized in our experiment leads to good absorption properties in the ultraviolet region. Upon excitation by the $320 \mathrm{~nm}$ ultraviolet photon, the intrinsic emission of $\mathrm{YVO}_{4}$ crystal is annihilated, and a broadband emission of $\mathrm{VO}_{4}^{3-}$ near $450 \mathrm{~nm}$ is observed at room temperature. The $\mathrm{YVO}_{4}$ phosphor powder synthesized at $180^{\circ} \mathrm{C}$ exhibits the maximum photoluminescence intensity, which is associated with the lower defect density caused by the higher crystalline quality under $180^{\circ} \mathrm{C}$.

\section{Acknowledgments}

We are grateful for the supports by the National Natural Science Foundation of China (grant No. 60807001), the Foundation of Young Key Teachers from University of Henan Province (grant No. 2011GGJS-008), the Foundation of Henan Educational Committee (grant No. 2010A140017) the Foundation of Graduate Innovation of Zhengzhou University (grant No. 12L00104) and the Foundation of Graduate Education Support of Zhengzhou University. 


\section{References}

[1] A.K. Levine, F.C. Palilla, Appl. Phys. Lett. 5, 118 (1964).

[2] H.J. Zhang, X.L. Meng, L. Zhu, P. Wang, X.S. Liu, Z.H. Yang, J. Dawes, P. Dekker, Phys. Status Solidi A 175, 705 (1999).

[3] A.R. Forbes, C.D. McMillen, H.G. Giesber, J.W. Kolis, J. Cryst. Growth 310, 4472 (2008).

[4] X.Y. Huang, Ph.D. Thesis, South China University of Technology, Guangzhou 2011 (in Chinese).

[5] P. Würfel, Physica E 14, 18 (2002).

[6] L. Aarts, B. van der Ende, M.F. Reid, A. Meijerink, Spectrosc. Lett. 43, 373 (2010).

[7] Z.H. Xu, X.J. Kang, C.X. Li, Z.Y. Hou, C.M. Zhang, D.M. Yang, G.G. Li, J. Lin, Inorg. Chem. 49, 6706 (2010).

[8] X.Y. Huang, J.X. Wang, D.C. Yu, S. Ye, Q.Y. Zhang, X.W. Sun, J. Appl. Phys. 109, 113526 (2011).

[9] H.Y. Xu, L. Jia, S.L. Xu, X.D. Li, H. Wang, H. Yan, Acta Chim. Sinica 63, 612 (2005) (in Chinese).

[10] X.Y. Huang, D.C. Yu, Q.Y. Zhang, J. Appl. Phys. 106, 113521 (2009).

[11] K.Y. Li, R.Z. Wang, M.H. Qu, Y. Zhang, H. Yan, Chin. J. Lumin. 33, 486 (2012).

[12] X.Y. Huang, Q.Y. Zhang, J. Appl. Phys. 105, 053521 (2009).
[13] X.C. Mi, Y.Y. Chen, Z.J. Wu, X.H. Liu, S.Y. Yang, L.C. Zhang, PARTA: Phys. Test. 40, 181 (2004) (in Chinese).

[14] X.Y. Fan, S.M. Ma, China Ceram. Indust. 9, 43 (2002) (in Chinese).

[15] X.Y. Gao, X.W. Liu, H.L. Feng, J.X. Lu, J. Zhengzhou Univ. (Nat. Sci. Ed.) 42, 51 (2010) (in Chinese).

[16] B. Jin, S. Erdei, A.S. Bhalla, F.W. Ainger, Mater. Lett. 22, 281 (1995).

[17] B.M. Jin, S. Erdei, A.S. Bhalla, F.W. Ainger, Mater Res. Bull. 30, 1293 (1995).

[18] J. Wang, Y.H. Xu, M. Hojamberdiev, J.H. Peng, G.Q. Zhu, J. Non-Cryst. Solids 355, 903 (2009).

[19] M. Yu, J. Lin, Z. Wang, J. Fu, S. Wang, H.J. Zhang, Y.C. Han, Chem. Mater. 14, 2224 (2002).

[20] L. Kovács, S. Erdei, R. Capelletti, Solid State Commun. 111, 95 (1999).

[21] H. Ronde, G. Blasse, J. Inorg. Nucl. Chem. 40, 215 (1978).

[22] G. Blasse, Philips Res. Rept. 24, 131 (1969).

[23] C. Hsu, R.C. Powell, J. Lumin. 10, 273 (1975).

[24] V. Pankratov, L. Grigorjeva, D. Millers, H.M. Yochum, Phys. Status Solidi C 4, 801 (2007). 